\title{
Outcomes of Tricuspid Regurgitation after Percutaneous Mitral Commissurotomy
}

\author{
Bryan Rene F. Toledano MD, ${ }^{1}$ Maria Johanna Jaluage-Villanueva $M . D,{ }^{2}$ Sharon Marisse Lacson $M . D^{2}$ \\ ${ }^{1}$ Senior Adult Cardiology Fellow in training, Philippine Heart Center \\ ${ }^{2}$ Consultant- Adult Cardiology, Echocardiography, Philippine Heart Center
}

Main Author: Bryan Rene F. Toledano, MD

E mail: imbryantoledano@gmail.com

Contact number: 09054776260

\begin{abstract}
\section{PURPOSE}

The gap in evidence in the management of multivalvular lesions can be addressed by providing more data on clinical and echocardiographic outcomes after Percutaneous Mitral commissurotomy (PMC).

\section{METHODS}

Participants were Filipinos aged $>/=19$ years old, admitted due to severe mitral stenosis with moderate to severe tricuspid regurgitation (TR). The outcome of PMC was divided into 2 groups: Significant TR which included the progression of moderate to severe TR or persistence of severe TR and Insignificant TR group which included those with mild TR, regression to moderate to mild TR, severe to moderate, or persistence of moderate TR. These groups were compared from baseline, 24th hour, 1st month, and 6th month using the same echocardiographic parameters. The numerical data between significant and nonsignificant tricuspid regurgitation were compared using non-parametric Mann Whitney $\mathrm{U}$ test and categorical data using the Chi-Square test.
\end{abstract}

\section{RESULTS}

A total of 38 participants were analyzed. On the 24th-hour postPTMC, the Significant TR group had significantly higher RAVI (42.3 vs 26.1, $p=.004$ ), RVD mid (3.81 vs 2.92, $p=.001$ ), SPAP (60.5 vs 38.5, $p=.003$ ), and RVOT (2.8 vs 2.2, $p=.001$ ) and lower MV planimetry (1.25 vs 1.58, $p=.009$ ); On the 1st-month RVD mid (3.4 vs 2.8, $p=.02$ ) and TV annulus (3.35 vs 2.76, $p=0.10$ ) were significantly higher in the Significant TR group; On the 6th month RAVI (59 vs 24.7, $p=.001$ ), RVD mid (4 vs $2.73, p=.006$ ), and TV annulus (4.5 vs $2.67 \mathrm{p}=.001$ ) were significantly higher in the Significant TR group when compared to Insignificant TR group.

\section{CONCLUSION}

PMC improved baseline parameters of SPAP, MV planimetry, MV gradient, and functional class on short-term follow-up on both groups of TR. Majority of outcomes after the procedure had insignificant TR. However, those with significant TR had higher RVD mid and TV annulus from the 24th hour to 6 months when compared to the insignificant TR group.

\section{KEYWORDS}

Rheumatic Heart Disease, Mitral stenosis, Percutaneous Mitral Commissurotomy

\section{INTRODUCTION}

Many Filipinos suffer from rheumatic heart diseases $(R H D)$ one of which is mitral stenosis (MS) and approximately $6 \%$ have tricuspid valve involvement. ${ }^{1}$ Based on our valve registry recorded last 2005 to $2007,28 \%$ of our admissions have severe MS. ${ }^{2}$ The Philippine Heart Center being a tertiary and referral institution receives symptomatic severe MS with combined multivalve lesions that needs mechanical intervention besides medical support. If we strictly follow the international guidelines for MS, most of our patients will need to undergo surgery instead of Percutaneous Mitral Commissurotomy (PMC) due to unfavorable clinical and anatomic characteristics. ${ }^{3}$ However, our resources are limited mainly due to cost and expertise. Many are left to endure limited functional capacity, increased risk for stroke, and poor quality of life while waiting to be operated on. One of the said contraindications for PTMC is concomitant severe tricuspid regurgitation (TR). Although mentioned that it may be considered in selected patients with sinus rhythm, moderate atrial enlargement, and functional TR secondary to pulmonary hypertension, most don't fit this criteria. ${ }^{3}$ Our institution tallied a total of 1586 PTMC procedures from 1989 to $2012 .{ }^{4}$ Since then, few retrospective unpublished studies regarding outcomes of TR after PMC were done. Both of these studies showed regression of moderate and severe TR, improvement of functional classification and other echocardiographic parameters such as tricuspid valve annulus, right atrial and ventricular diameter and pulmonary artery pressure on short and long term follow up., ${ }^{5,}$ Similarly, international studies from developing countries where MS secondary to RHD are endemic supports that PMC in severe MS with significant TR does regress and is directly related to factors such as the severity of mitral stenosis, pulmonary artery pressure, and right ventricular diameter. $7,8,9$ The gap in evidence concerning combined and multi-valve disease in MS can be addressed by providing more data on the natural history and impact of the intervention on the clinical and echocardiographic outcome that will better define the indications for PMC.

\section{RESEARCH OBJECTIVES}

a. General Objectives

To compare the clinical and echocardiographic parameters among significant and nonsignificant Tricuspid Regurgitation after Percutaneous Mitral Commissurotomy

b. Specific Objectives

To describe the outcomes of PTMC in patients with moderate to severe TR

To compare the echocardiographic data among cases of significant and nonsignificant TR at the 24th hour, 1st, and 6th months after PTMC 


\section{METHODOLOGY}

The design is a prospective cohort study, which included all patients aged 19 years old and above with rheumatic MS admitted at the Philippine Heart Center between January 2019 to October 2020 for PMC due to symptomatic severe MS with concomitant moderate to severe TR. The TR may be functional or organic with or without other associated valve lesions. Baseline clinical characteristics, anthropometric data, functional capacity, and two-dimensional transthoracic echocardiogram with doppler (2DED) were done before the PMC within the admission, after 24 hours, on outpatient at 1 month and 6 months. An echo machine, using the latest Siemens model, and certified echo sonographers were used in the study. A sole designated echocardiographer level III served as the reader of the 2DED studies. The participants were asked to follow up using a phone call to arrange the meeting, with a window period of one week from the time of the original schedule for checkup and outpatient 2DED in our institution. The outcome of PMC was divided into 2 groups the Significant TR which included the progression of moderate TR to severe or the persistence of severe TR and the Insignificant TR group which included those with mild TR, regression of moderate TR to mild, severe TR to moderate or persistence of moderate TR after PTMC. These groups were compared from baseline, 24th hour, 1st month, and 6th month using the same echocardiographic parameters. For participants who were not able to follow up in our institution for checkup and outpatient 2DED due to travel restrictions imposed by COVID. The 2DED evaluation is forfeited however they were asked to follow up with their local Internal Medicine specialist or Cardiologist for assessment of functional capacity and anthropometric data. The approach and grading of valve lesions were based on established international guidelines..$^{10,1}$

\section{Operational definition}

1. Significant TR - progression of moderate TR to severe or, persistence of severe TR after PMC

2. Insignificant TR- mild TR, regression of mild to no TR, moderate to mild TR, severe to moderate TR or persistence of mild or moderate TR after PMC

3. New York Heart Association (NYHA) Classificationassessment of functional capacity done by a cardiologist or internal medicine specialist

NYHA I - No limitation of physical activity. Ordinary physical activity (e.g., walking, climbing stairs) does not cause any symptoms of heart failure (e.g., dyspnea, fatigue, and decreased exercise tolerance)

NYHA II - Slight limitation of physical activity. Comfortable at rest but ordinary physical activity results in symptoms of heart failure

NYHA III - Marked limitation of physical activity. Comfortable at rest, but less ordinary physical activity e.g., walking short distances (e.g., 20-100 yards) causes symptoms of heart failure

NYHA IV - Unable to carry on any physical activity without symptoms of heart failure or heart failure at rest

4. Body mass index - calculated as the weight in kilograms divided by the square of the height in meters, categories are: underweight $\left(<18.5 \mathrm{~kg} / \mathrm{m}^{2}\right)$, normal $\left(18.5-24.9 \mathrm{~kg} / \mathrm{m}^{2}\right)$, overweight $\left(25-29.9 \mathrm{~kg} / \mathrm{m}^{2}\right)$, obese $\left(>/=30 \mathrm{~kg} / \mathrm{m}^{2}\right)$

5. Left Ventricular Internal Dimension - normal diastolic dimension (LVEDD) in cm (4.2-5.84) males, (3.78-5.22) females, normal systolic dimension (LVESD) in cm (2.5- 3.98) males, (2.16-3.48) females ${ }^{12}$

6. Left ventricular (LV) remodeling- based on the measurement of left ventricular mass index (LVMI) normal is $</=115$ in males, $</=96$ in females and relative wall thickness (LVRT) normal is $</=0.42$. Concentric remodeling (normal LVMI and increase LVRT), Eccentric hypertrophy (increase LVMI, normal LVRT) and concentric hypertrophy (increase LVMI and LVRT) ${ }^{12}$

7. Ejection fraction (EF) - normal range (52-72) males, (54-74) females. ${ }^{12}$

8. Left atrial volume index ( $\mathrm{LAVI}$ ) - measured in $\mathrm{ml} / \mathrm{m} 2$ normal (16-34), mild dilatation (35-41), Moderate dilatation (42-48) and severe dilatation $>48^{12}$

10. Right atrial volume index (RAVI) - measured in $\mathrm{ml} / \mathrm{m}^{2}$ normal (15-27) females and (18-32) males $^{12}$

9. Right ventricular fractional area change (RVFAC) - normal is $>35 \%{ }^{12}$

10. Right ventricular dimension mid (RVD) - measured in $\mathrm{cm}$ at the two-dimensional echo and mid-level, normal is (1.9-3.5 $)^{12}$

11. Systolic pulmonary arterial pressure (SPAP)- measured in $\mathrm{mmHg}$, normal is (18-34), mild (35-59), moderate (60-79) and severe $(>80)^{12}$

12. Mitral valve (MV) planimetry - measured in $\mathrm{cm}^{2}$ mild is ( $\left.>1.5\right)$, moderate $(1-1.5)$ and severe $(<1.0)^{12}$

13. MV mean gradient - measured in $\mathrm{mmHg}$ mild is $(<5)$, moderate $(5-10)$ and severe $(>10)^{12}$

14. Tricuspid valve annulus- measured in $\mathrm{cm}$ normal is (1.3$2.8 \mathrm{~cm})^{12}$

15. Pulmonic valve annulus- measured in $\mathrm{cm}$ normal is (1.7$2.3 \mathrm{~cm})^{12}$

16. Left ventricular outflow tract - measured in $\mathrm{cm}$ normal is (1.8$2.4)^{12}$

17. Right ventricular outflow tract - measured in $\mathrm{cm}$ normal is (2.1-3.5) females and (1.7-2.7) males $^{12}$

\section{Data organization, editing, processing, and analysis}

The data obtained were checked for completeness and categorized into 4 types per time of 24th hour, 1st month and 6th month using Microsoft Excel (version 16.30): 1. Echocardiographic parameters of Significant tricuspid regurgitation 2. Echocardiographic parameters of Insignificant tricuspid regurgitation 3. Clinical characteristics of Significant tricuspid regurgitation 4. Clinical characteristics of Insignificant tricuspid regurgitation. The rechecking of data was done twice to ensure correctness and validity.

\section{Statistical Analysis}

All analyses were done using the Statistical Package for the Social Sciences Version 23 (SPSS, Chicago, III.) Numerical data were summarized as means and with their standard deviation and interquartile ranges while categorical data were presented as percentages. Comparison of numerical data between significant and nonsignificant tricuspid regurgitation categories was done using non-parametric Mann Whitney $U$ test. Categorical data were compared using Chi-Square test. All $p$-values less than .05 were considered statistically significant.

\section{RESULTS}

From January 2019 to October 2020, the institution documented a total of 38 cases of severe MS with moderate to severe TR for PMC (Figure-1). Their clinical profile is summarized (Table-1). Among those with significant TR, the mean age was 42 years old, with female predominance (84.2\%), and was mostly classified in NYHA II (92.1\%). Atrial fibrillation was noted in (68.4\%) while sinus rhythm was noted in $(31.6 \%)$. Of this sample, $(73.7 \%)$ had normal BMI. Two patients (5.3\%) had a previous PTMC. The 
Figure 1: Study flow chart

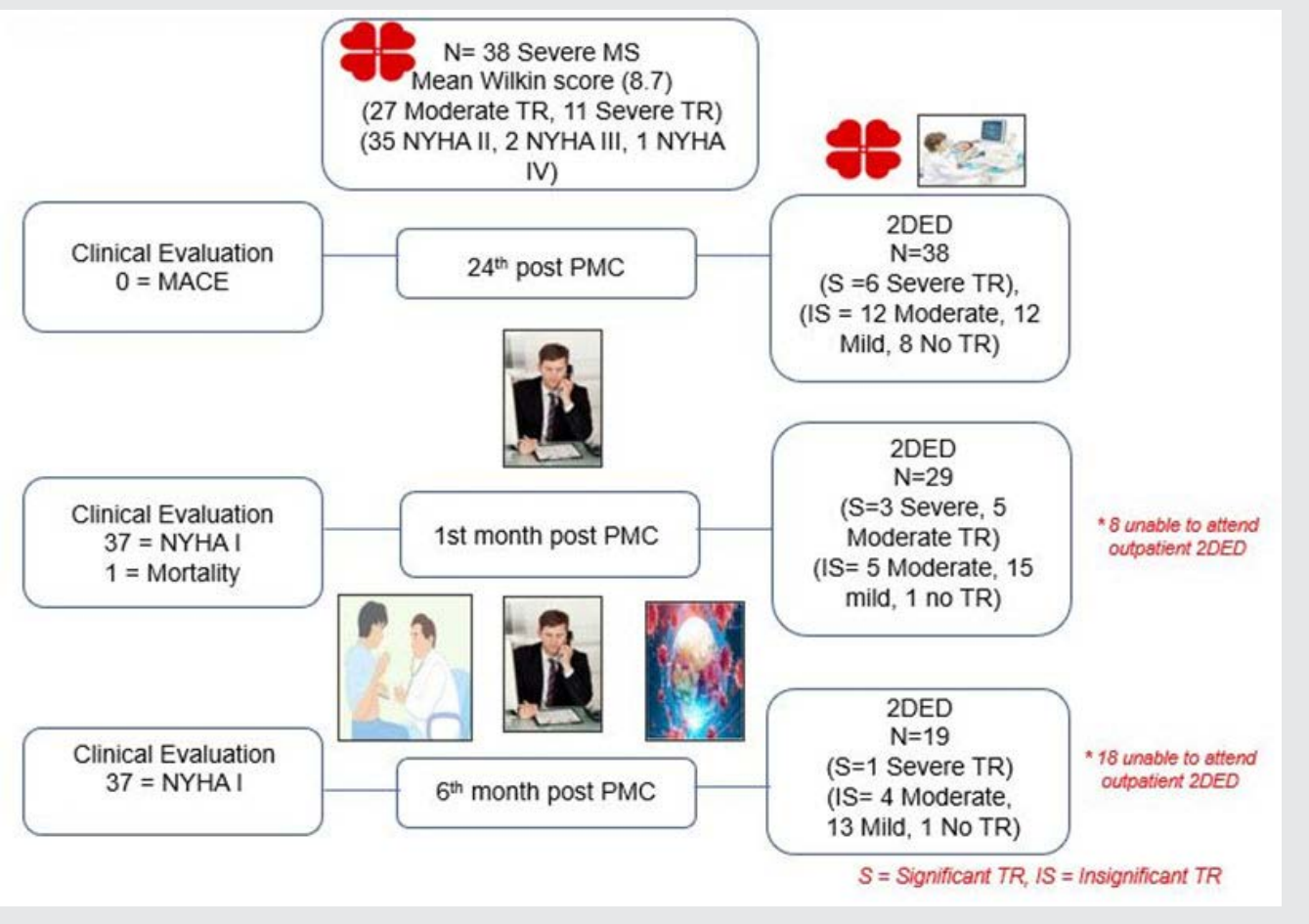

Table 1. Baseline Characteristics of Severe Symptomatic Mitral Stenosis with Significant Tricuspid Regurgitation, Philippine Heart Center, 2019-2020

Characteristics

\begin{tabular}{lc} 
Age & $42 \pm 11.3(44.5)$ \\
\hline Sex & $6(15.8)$ \\
Male & $32(84.2)$ \\
Female & \\
\hline
\end{tabular}

\section{NYHA}

I

II

III

IV

Rhythm

SR

AF

\begin{tabular}{lc}
\hline Height (meters) & $1.57 \pm .058(1.57)$ \\
\hline Weight (kg) & $55.3 \pm 8.8(54.5)$ \\
\hline Body mass index & $5(13.2)$ \\
\hline Underweight & $28(73.7)$ \\
Normal & $5(13.1)$ \\
Overweight & 0 \\
Obese & $2(5.3)$ \\
\hline Previous PTMC & $26.8 \pm 25.1(12)$ \\
\hline Diagnosis to PTMC time (months) & $10(26.3)$ \\
\hline History of stroke/TIA & $8.7 \pm 0.8(8)$ \\
Wilkin's score (Total) & $2.1 \pm 0.2$ \\
Leaflet mobility (mean) & $2.2 \pm 0.4$ \\
Valve thickness (mean) & $2.1 \pm 0.3$ \\
Valvular calcification (mean) & $2.2 \pm 0.4$ \\
Subvalvular thickening (mean) &
\end{tabular}

Percentage values in () reflect vertical sum, IQR are enclosed in () after the mean average duration of time of diagnosis to the procedure was 26.8 months. Ten cases had a stroke (26.3\%) before the intervention. The average total Wilkin score was 8.7. The mean score for leaflet mobility, valve thickness, valvular subcalcification, and subvalvular thickening are displayed. (Table-1)

The baseline echocardiographic parameters measured prior to PTMC showed normal mean values of LVEDD, LVESD, LVMI, RAVI, RVFAC, RVD mid, PV annulus LVOT and RVOT. The mean values of LVRT, LAVI, PA pressure, MV gradient, TV annulus were elevated while MV planimetry was small as displayed. (Table-2)

Table 2. Baseline echocardiographic data of severe mitral stenosis with moderate to severe tricuspid regurgitation, Philippine Heart Center, 2019-2020

\begin{tabular}{lcc} 
& Mean & SD \\
No. of patients & 38 & -- \\
\hline LVEDD & 4.1 & 0.49 \\
\hline LVESD & 2.8 & 0.44 \\
\hline LVMI & 81.4 & 18.7 \\
\hline LVRT & 0.44 & 0.10 \\
\hline EF by Simpson & 59.2 & 7.7 \\
\hline LAVI & 65.2 & 19.7 \\
\hline RAVI & 29.6 & 7.3 \\
\hline RVFAC & 44.9 & 7.9 \\
\hline RVD mid & 3.1 & 0.74 \\
\hline PA Pressure & 68 & 27.8 \\
\hline MV planimetry & 0.71 & 0.19 \\
\hline MV gradient & 15.7 & 5.3 \\
\hline Tricuspid valve annulus & 3.0 & 0.51 \\
\hline Pulmonic valve annulus & 2.27 & 0.39 \\
\hline LVOT & 1.8 & 0.19 \\
\hline RVOT & 2.4 & 0.50 \\
\hline
\end{tabular}


The echocardiographic parameters measured 24-hours post PMC showed significantly higher RAVI among those with significant TR (mean 42.3 versus 26.1, $p=.004$ ), higher RVD mid (mean 3.81 versus 2.92, $p=.001$ ), higher PA pressure (mean 60.5 versus 38.5, $p=.003$ ), larger for TV annulus (mean 3.46 versus 2.8, $\mathrm{p}=.002$ ) and RVOT (mean 2.8 versus $2.2, \mathrm{p}=.001$ ). MV planimetry was smaller in those with significant TR (mean 1.25 versus $1.58, \mathrm{p}=.009$ ). (Table-3)

\begin{tabular}{lccc}
\hline \multicolumn{4}{l}{$\begin{array}{l}\text { Table 3. Comparison in Echocardiographic data of Significant and Insignificant Tricuspid } \\
\text { Regurgitation from baseline to 24th hour post PMC, Philippine Heart Center, 2019-2020 }\end{array}$} \\
$\begin{array}{l}\text { Significant TR } \\
\text { Mean }(S D)\end{array}$ & Insignificant TR & P-value \\
No. of patients & 6 & 32 & \\
\hline LVEDD & $4.3(0.61)$ & $4.4(0.37)$ & 0.52 \\
\hline LVESD & $2.86(0.54)$ & $2.81(0.41)$ & 0.77 \\
\hline LVMI & $88.67(49.3)$ & $80.5(19.8)$ & 0.48 \\
\hline LVRT & $0.41(0.16)$ & $0.40(0.11)$ & 0.87 \\
\hline EF by Simpson & $62(3.8)$ & $64.5(6.3)$ & 0.35 \\
\hline LAVI & $59.7(39)$ & $55.7(18.2)$ & 0.69 \\
\hline RAVI & $42.3(10.3)$ & $26.1(12.1)$ &. $\mathbf{0 0 4}$ \\
\hline RVFAC & $43.2(9.6)$ & $48.5(7.5)$ & .14 \\
\hline RVD mid & $3.81(0.53)$ & $2.92(0.51)$ & $\mathbf{. 0 0 1}$ \\
\hline PA Pressure & $60.5(18.4)$ & $38.5(15.2)$ & $\mathbf{. 0 0 3}$ \\
\hline MV planimetry & $1.25(0.13)$ & $1.58(0.28)$ & $\mathbf{. 0 0 9}$ \\
\hline MV gradient & $5.16(1.6)$ & $5.43(1.7)$ & .73 \\
\hline Tricuspid valve annulus & $3.46(0.29)$ & $2.8(0.45)$ & $\mathbf{. 0 0 2}$ \\
\hline Pulmonic valve annulus & $2.4(0.22)$ & $2.2(0.41)$ & .26 \\
\hline LVOT & $1.8(0.21)$ & $1.85(0.22)$ & .58 \\
\hline RVOT & $2.8(0.35)$ & $2.2(0.31)$ & $\mathbf{. 0 0 1}$ \\
\hline S & & \\
\hline
\end{tabular}

*Significant $p$-values if $p$ is $<.05$, Mann Whitney $U$ test

The echocardiographic parameters measured 1-month post PMC showed that those with significant TR had higher RVD mid values (mean 3.4 versus 2.8, $p=.02$ ), larger TV annulus values (mean 3.35 versus $2.76, p=.010$ ). The rest of the echocardiographic parameters were not significantly different between the two groups compared. (Table-4)

\begin{tabular}{|c|c|c|c|}
\hline & $\begin{array}{l}\text { Significant TR } \\
\text { Mean (SD) }\end{array}$ & Insignificant TR & P-value \\
\hline No. of patients & 8 & 21 & \\
\hline LVEDD & $4.4(0.51)$ & $4.3(0.44)$ & .55 \\
\hline LVESD & $3.01(0.56)$ & $2.89(0.38)$ & .51 \\
\hline LVMI & $94.1(38.1)$ & $86.2(26.1)$ & .52 \\
\hline LVRT & $0.39(.039)$ & $0.40(0.09)$ & .88 \\
\hline EF by Simpson & $61.7(4.5)$ & $63.2(4.7)$ & .45 \\
\hline LAVI & $70.3(32.3)$ & $55.9(23.0)$ & .18 \\
\hline RAVI & $36.1(18.3)$ & $25(12.9)$ & .07 \\
\hline RVFAC & $46.3(7.5)$ & $47.3(5.7)$ & .71 \\
\hline RVD mid & $3.4(0.85)$ & $2.8(0.44)$ & .02 \\
\hline PA Pressure & $51.8(22.9)$ & $41.0(24.3)$ & .28 \\
\hline MV planimetry & $1.43(0.19)$ & $1.39(0.25)$ & .71 \\
\hline MV gradient & $5.7(2.5)$ & $6.1(1.7)$ & .65 \\
\hline Tricuspid valve annulus & $3.35(0.80)$ & $2.76(0.34)$ & .010 \\
\hline Pulmonic valve annulus & $2.21(0.31)$ & $2.17(0.35)$ & .77 \\
\hline LVOT & $1.86(0.23)$ & $1.85(0.19)$ & .91 \\
\hline RVOT & $2.43(0.36)$ & $2.33(0.37)$ & .52 \\
\hline
\end{tabular}

*Significant $p$-values if $p$ is $<.05$, Mann Whitney $U$ test 
The echocardiographic parameters measured 6 months post-PTMC showed that those with significant TR had significantly higher values for RAVI (mean 59 versus 24.7, $p=.001$ ); RVD mid (mean 4.0 versus 2.73 , $\mathrm{p}=.006)$ and tricuspid valve annulus (mean 4.5 versus 2.67, $\mathrm{p}=.001$ ). The other echocardiographic parameters did not significantly vary between the two groups (all p-values >.05) (Table-5)

A comparative profile of cases of the baseline characteristics and classification of significant and insignificant TR on 2DED at 24 hours post-PTMC to the clinical characteristics at six months was made (Table 6). A higher proportion of those who had nonsignificant TR were classified as NYHA Class I ( $86.5 \%$ versus $13.5 \%, p=.019)$; they were also heavier (mean 58.5 versus $47.7 \mathrm{~kg}, p=.042$ ). The mean total Wilkin score was statistically higher among those with significant TR (mean 9.6 versus $8.5, p=.003$ ). Higher mean scores were given to valve thickness (mean 2.6 versus 2.1, $\mathrm{p}=.006)$ and valvular calcification (mean 2.5 versus $2.1, p=.030$ ). No differences were noted in terms of the age, sex distribution, rhythm, height, body mass index, the proportion of cases with previous PMC, duration of time from diagnosis to PTMC, and the history of stroke (all p-values $>.05$ )

\begin{tabular}{|c|c|c|c|}
\hline & $\begin{array}{l}\text { Significant TR } \\
\text { Mean (SD) }\end{array}$ & Insignificant TR & P-value \\
\hline No. of patients & 1 & 18 & \\
\hline LVEDD & 4.0 & $4.6(0.43)$ & .18 \\
\hline LVESD & 2.7 & $2.9(0.48)$ & .61 \\
\hline LVMI & 79 & $86.1(25.9)$ & .79 \\
\hline LVRT & 0.55 & $0.37(0.08)$ & .059 \\
\hline EF by Simpson & 54 & $62.1(5.1)$ & .13 \\
\hline LAVI & 100 & $52.9(27.1)$ & .11 \\
\hline RAVI & 59 & $24.7(7.6)$ & .001 \\
\hline RVFAC & 54 & $47.3(7.3)$ & .38 \\
\hline RVD mid & 4.0 & $2.73(0.39)$ & .006 \\
\hline PA Pressure & 45 & $39.2(9.1)$ & .55 \\
\hline MV planimetry & 1.46 & $1.41(0.23)$ & .85 \\
\hline MV gradient & 4.2 & $6.5(3.3)$ & .49 \\
\hline Tricuspid valve annulus & 4.5 & $2.67(0.36)$ & .001 \\
\hline Pulmonic valve annulus & 2.4 & $2.1(0.29)$ & .37 \\
\hline LVOT & 2.2 & $1.90(0.17)$ & .11 \\
\hline RVOT & 2.8 & $2.2(0.31)$ & .12 \\
\hline
\end{tabular}

*Significant $p$-values if $p$ is $<.05$, Mann Whitney $U$ test

\begin{tabular}{|c|c|c|c|}
\hline Characteristics & Significant TR & Insignificant TR & P-value \\
\hline Age & $39.6(18.3)$ & $43.1(9.8)$ & .50 \\
\hline \multicolumn{4}{|l|}{ Sex } \\
\hline Male & $1(16.7)$ & $5(83.3)$ & .94 \\
\hline Female & $5(15.6)$ & $27(84.4)$ & \\
\hline \multicolumn{4}{|l|}{ NYHA } \\
\hline 1 & $5(13.5)$ & $32(86.5)$ & $.019^{\star \star}$ \\
\hline$\|$ & 0 & 0 & \\
\hline III & 0 & 0 & \\
\hline IV & 1 & 0 & \\
\hline \multicolumn{4}{|l|}{ Rhythm } \\
\hline $\mathrm{SR}$ & $2(16.7)$ & $10(83.3)$ & .06 \\
\hline AF & $3(12)$ & $22(88)$ & \\
\hline Height (meters) & $1.6(.07)$ & $1.57(.05)$ & .24 \\
\hline Weight (kg) & $47.7(24.3)$ & $58.5(7.5)$ & $.042^{\star}$ \\
\hline \multicolumn{4}{|l|}{ Body mass index } \\
\hline Underweight & 0 & $1(100)$ & .29 \\
\hline Normal & $5(19.2)$ & $21(80.8)$ & \\
\hline Overweight & 0 & $10(100)$ & \\
\hline Obese & 0 & 0 & \\
\hline Previous PTMC & 0 & $2(100)$ & .52 \\
\hline Diagnosis to PTMC time (months) & $26.6(28.1)$ & $26.9(24.9)$ & .98 \\
\hline History of stroke/TIA & $1(11.1)$ & $8(88.9)$ & .80 \\
\hline Wilkin's score (Total) & $9.6(1.0)$ & $8.5(0.76)$ & $.003^{\star}$ \\
\hline Leaflet mobility (mean) & $2.1(0.4)$ & $2.0(0.24)$ & .39 \\
\hline Valve thickness (mean) & $2.6(0.51)$ & $2.1(0.36)$ & $.006^{\star}$ \\
\hline Valvular calcification (mean) & $2.5(0.54)$ & $2.1(0.33)$ & $.030^{\star}$ \\
\hline Subvalvular thickening (mean) & $2.3(0.51)$ & $2.1(0.39)$ & .43 \\
\hline
\end{tabular}

Significant difference if $p$-value is $<.05,{ }^{*}$ Mann Whitney $U$ test, ${ }^{* *}$ Chi-Square Test The echocardiographic parameters from baseline to 6th month of follow up is summarized in (Figure-2). 
Figure 2: Line graphs of echocardiographic parameters from baseline to 6th month of follow up

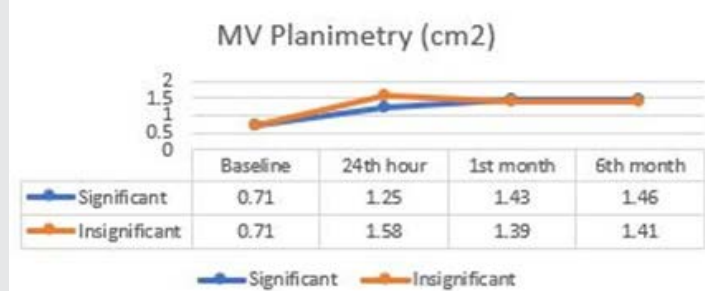

Significant difference on the $24^{-}$hour $(\mathrm{p}=0.009)$ No significant differences on the $1^{\text {st }}(p=0.71), \sigma^{\text {nn }}$ month $(0.85)$

RVFAC (\%)

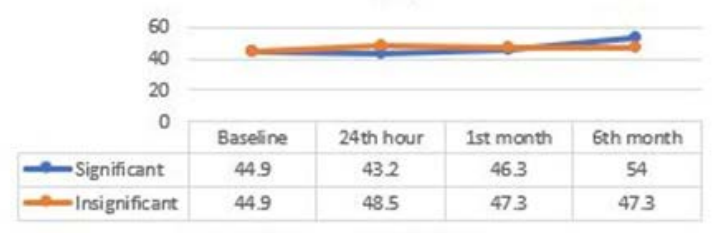

-Significant Insigrificant

No significant differences on the $24^{\text {n }}$ hour $(p=0.14)$ $1^{\text {tz }}(\mathrm{p}=0.71), 6^{\mathrm{m}}$ month $(0.38)$

LAVI $(\mathrm{ml} / \mathrm{cm} 2)$

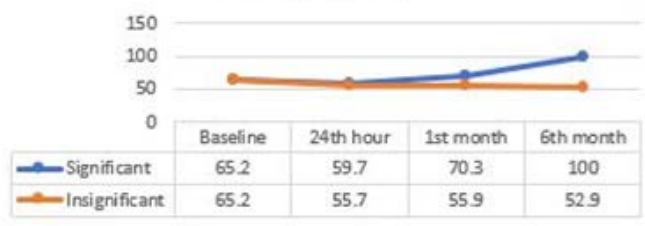

-Significant -insignificant

No significant differences on the $24^{* \prime \prime}$ hour $(p=0.69)$

$1^{\text {th }}(p=0.18), 6^{\text {th }}$ month $(0.11)$

SPAP (mmhg)

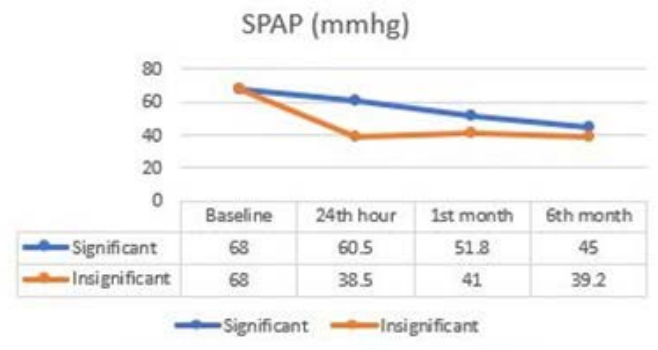

Significant difference on the $24^{\text {n }}$ hour $(p=0.003)$

No significant differences on the
$1^{11}(p=0.28), 6^{n}$ month $(p=0.55)$

TV Annulus $(\mathrm{cm})$

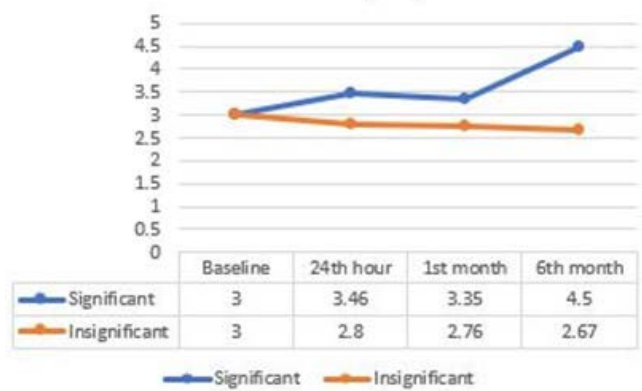

Significant difference on the $24^{m}$ hour $(p=0.022), 1^{* \prime}(p=0.010)$, and $6^{\text {m }}$ month $(p=0.001)$

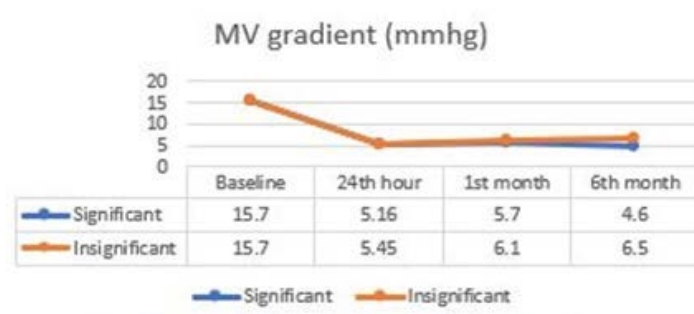

No significant differences on the $24^{\text {m }}$ hour $(p=0.73)$ $1^{\text {ta }}(p=0.65), 6^{n}$ month $(0.49)$

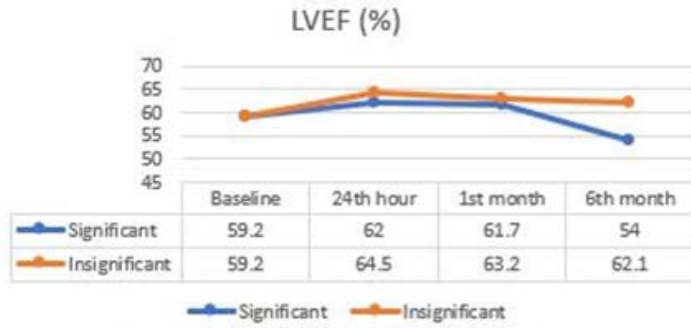

No significant differences on the $24^{n}$ hour $(p=0.38)$ $1^{\text {st }}(p=0.45), 6^{n}$ month $(0.13)$

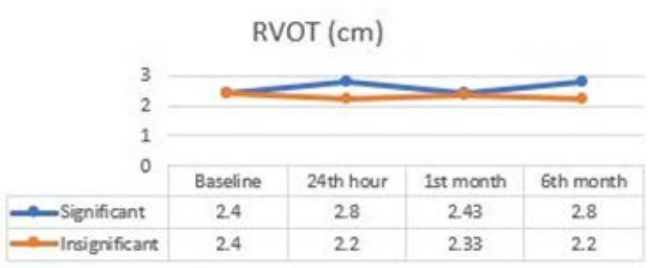

-Significant $\longrightarrow$ Insigrificant

Significant difference on the $24^{n}$ hour $(p=0.001)$ No significant differences on the

$\mathrm{RAVI}(\mathrm{ml} / \mathrm{cm} 2)$

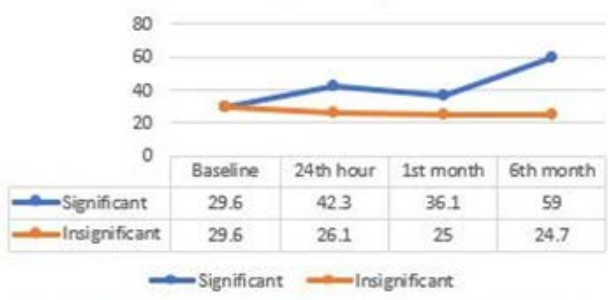

Significant difference on the $24^{\mathrm{m}}$ hour ( $\left.\mathrm{p}=0.044\right)$, and $6^{\mathrm{m}}$ month ( $\mathrm{p}=$ 0.001 )

No significant differences on the $1^{\text {at }}(p=0.07)$

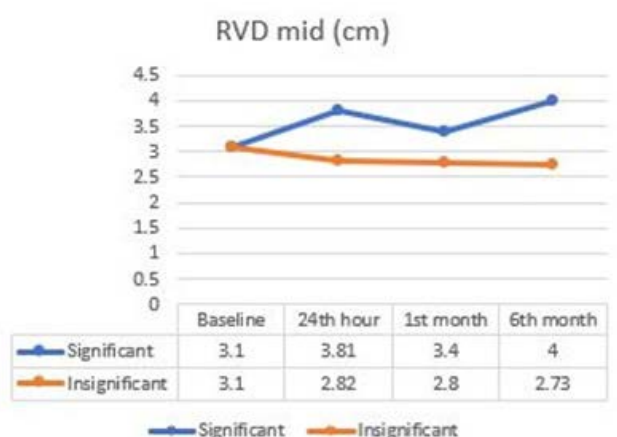

Significant difference on the $24^{\mathrm{m}}$ hour $(p=0.001), 1^{\text {st }}(p=0.02)$, and $6^{\mathrm{m}}$ month $(p=0.006)$ 


\section{DISCUSSION}

Most of the participants belonged to the middle-aged group together with the long interval between the diagnosis of RHD with MS to the intervention of almost two years. The factors of cost, geographic location, reluctance, and availability of the procedure may have contributed. The participants were dominated by females, the cause of this association is unknown. ${ }^{13}$ It is when patients experienced dyspnea, fatigue, decreased exercise intolerance at work or during labor that they were first diagnosed. Some were referred for evaluation and treatment before noncardiac surgery or recently discovered valvular atrial fibrillation that suffered an embolic stroke. Atrial fibrillation is the most common complication, and the prevalence is related to the severity of obstruction and the patient's age. ${ }^{14}$ The participants with baseline NYHA III had orthopnea and were previously admitted for pulmonary congestion. One patient on NYHA IV had high-risk pneumonia and was on mechanical ventilatory and vasopressor support.

The baseline echocardiographic parameters demonstrated average values of normal LV volume, function, LVMI, and somewhat increased LVRT. A typical normal or small LV is expected because the obstruction had left the receiving chamber underfilled. However specific patterns of LV remodeling may be related to compensation of a low cardiac output or coexisting valvular or myocardial abnormalities. ${ }^{15}$ Severe mitral stenosis reflected a very small MV planimetry, high MV gradient, and dilated LAVI. The combination of obstruction and moderate to severe tricuspid regurgitation in this group led to hemodynamic consequences of a dilated TV annulus and increased SPAP. The other right-sided parameters that may also have secondary effects due to pressure and volume overload had normal average values at baseline.

The relief of obstruction brought about by PMC thru commissural separation and fracture of nodular calcium had physiologically caused a reduction of pressure to the left atrial, pulmonary vascular, and the right-sided structures. At the 24th hour after the procedure, echocardiographic data revealed 6 out of 38 participants that had significant TR. When compared to the insignificant TR group, those in the significant TR group had significantly larger RAVI, RVD mid, RVOT, and TV annulus, higher SPAP, and lower MV planimetry. On further follow-up, during the first and sixth months after PTMC, the echocardiographic data revealed 8 out of 29 and 1 out of 19 participants had significant TR. After 1 month a larger RVD mid and TV annulus and after 6th months a larger RAVI, RVD mid and TV annulus persisted, among the significant TR group.

The baseline change of SPAP, MV planimetry, and MV gradient after PMC in both groups is responsible for the improvement of the functional class seen in the participants we were followed up with. Almost all were in NYHA class I at 1st and 6th-month post PMC aside from this they did not suffer any complications such as stroke nor infective endocarditis. The improvement of the functional class was in those with baseline NYHA II-III, the majority were able to work and tolerated a successful noncardiac surgery. One case with NYHA IV had emergent PMC and died due to sepsis. There were few studies regarding the role of emergent PTMC in NYHA class IV, both advocated that PMC may be done in critically ill patients and if surgery carries a high prohibitive risk, however, the prognosis was still dismal. ${ }^{15-16}$

The most studied association of the improvement after PMC is the reduction of pulmonary artery systolic pressure. ${ }^{8,9}$ In our study, a continuous drop of SPAP was seen from baseline to 6th month in the significant group while in the insignificant group an initial drop which then plateaued on the 1st and 6th month period was seen. Hence PMC can reduce SPAP in both groups however reversion to normal pulmonary pressure may not be possible due to the chronicity and the adaptive changes of pulmonary arteriolar constriction and organic obliteration of pulmonary vasculature. A lack of significant improvement and difference in LAVI between the two groups was evident. It may be associated with the long-standing and permanent damage to the left atrium as reflected by a high percentage of atrial fibrillation. ${ }^{16} \mathrm{~A}$ continuous improvement of RAVI, RVD mid and TV annulus were seen from baseline to 6th months but only in the insignificant group as also seen in other retrospective studies. ${ }^{6,7}$ The RAVI, RVD mid, and TV annulus measurements should be monitored in the significant TR group as these parameters may be used for detection, risk stratification, and initiation of therapy in right heart failure. ${ }^{17,} 18,19$

The classification of six significant and thirty-two insignificant TR at 24th-hour post-PTMC showed that the significant TR group have a significantly higher Wilkin score at 9.6 and the components of valvular thickness and calcifications were significantly higher. These parameters may correlate with the mitral stenosis severity and the higher volume and pressure from the obstruction hence differences between the two groups were evident. The Wilkin score is the most validated parameter that predicts immediate and long-term morbidity and mortality, ${ }^{20}$ incorporation of associated valve lesion such as TR may better elucidate the course of the disease. Lower body weight was seen in the significant TR group on follow-up. The value of this parameter is yet to be explored but it may herald a possible cardiac cachexia ${ }^{21}$ due to worsening valve lesion in patients with persistent significant tricuspid regurgitation.

\section{LIMITATIONS \& RECOMMENDATION}

The unfortunate effects of the COVID pandemic had brought the cases down of elective PMC procedure hence an adequate sample size to represent both groups were not attained. The dropout rates for the acquisition of 2DED data were $22 \%$ at 1 month and $49 \%$ at the 6 th month. The lockdown instituted to the different parts of our country precluded the participants from the scheduled date of 2DED at our institution. The percentage that belonged to significant TR group was (16\%) at 24th hour, (27\%) at $1 \mathrm{st}$ month and (5\%) at 6 th month. The high dropout rates may have altered the true incidence of each group. We recommend a larger sample size and low dropout rates to predict the factors of outcome for each group. Also, the determination of factors associated or predictive of functional class or major cardiovascular events would have a greater impact on management.

\section{CONCLUSION}

PMC improved baseline parameters of SPAP, MV planimetry, MV gradient and functional class on short term follow up on both groups of TR. Majority of outcomes after the procedure had insignificant TR. However, those with significant TR had higher RVD mid and TV annulus from 24th hour to 6 months when compared to insignificant TR group which should be monitored and correlated with clinical status. 


\section{REFERENCES}

1. Mann DL, Zipes DP, Libby P, Bonow RO, and Braunwald, E. Braunwald's heart disease: A textbook of cardiovascular medicine (Eleventh edition). 2015. Philidelphia, PA: Elesevier/Saunders.

2. Don MRA. Sarmiento FM. Saludes H. and Torio R. Valve Registry, The Philippine Heart Center Experience, Year 2005-2007. 2008. Unpublished.

3. Helmut Baumgartner, Volkmar Falk, Jeroen J Bax, Michele De Bonis, Christian Hamm, Per Johan Holm, Bernard lung, Patrizio Lancellotti, Emmanuel Lansac, Daniel Rodriguez Muñoz, Raphael Rosenhek, Johan Sjögren, Pilar Tornos Mas, Alec Vahanian, Thomas Walther, Olaf Wendler Stephan Windecker, Jose Luis Zamorano, ESC Scientific Document Group, 2017 ESC/EACTS Guidelines for the management of valvular heart disease, European Heart Journal, Volume 38, Issue 36, 21 September 2017, Pages 2739-2791.

4. Jara RD and Tumabiene KD. Valvuloplasty for Rheumatic Mitral Stenosis: The Philippine Experience. 2013. Philippine Heart Center Journal.

5. Lotilla WS, Cayetano JF, Lim AC, et al. Outcome of Moderate to Severe Tricuspid Regurgitation Associated with Dilated Tricuspid Valve Annulus Following Successful Percutaneous Transeptal Mitral Commissurotomy Unpublished. On file. Department of Adult Cardiology, Philippine Heart Center.

6. Ang A. and Tria A. Immediate and long-term outcomes of Significant Tricuspid Regurgitation After Percutaneous Mitral Vallon Valvotomy. 2004

7. Hannoush H, Fawzy ME, Stefadouros M, Moursi M, Chaudhary MA, Dunn B. Regression of significant tricuspid regurgitation after mitral balloon valvotomy for severe mitral stenosis. Am Heart J. 2004 Nov; 148(5):865-70. doi: 10.1016/j.ahj.2004.05.017. PMID: 15523319.

8. Ghaffari S, Salehi R, Goldost Juibary M, Abbasnejad M. The Outcome of Tricuspid Regurgitation after Mitral Balloon Valvutomy for Severe Mitral Stenosis, Int Cardio Res J. 2009; 3(4): e67878.

9. Zoroufian A. Tricuspid Regurgitation Improvement in Relation to the Amount of Pulmonary Artery Pressure Reduction: reply. J Tehran Heart Cent. 2010 Fall;5(4):210-1. Epub 2010 Sep 30. PMID: 23074597; PMCID: PMC3466850.

10. Zoghbi WA, Adams D, Bonow RO, Enriquez-Sarano M, Foster E, Grayburn PA, Hahn RT, Han Y, Hung J, Lang RM, Little SH, Shah DJ, Shernan S, Thavendiranathan P, Thomas JD, Weissman NJ. Recommendations for Noninvasive Evaluation of Native Valvular Regurgitation: A Report from the American Society of Echocardiography Developed in Collaboration with the Society for Cardiovascular Magnetic Resonance. J Am Soc Echocardiogr. 2017 Apr;30(4):303-371. doi: 10.1016/j.echo.2017.01.007. Epub 2017 Mar 14. PMID: 28314623.

11. Helmut Baumgartner, Judy Hung, Javier Bermejo, John B. Chambers, Arturo Evangelista, Brian P. Griffin, Bernard lung, Catherine M. Otto, Patricia A. Pellikka, Miguel Quiñones, Echocardiographic assessment of valve stenosis: EAE/ASE recommendations for clinical practice, European Journal of Echocardiography, Volume 10, Issue 1, January 2009, Pages 1-25, https://doi.org/10.1093/ejechocard/jen303

12. Lang RM, Badano LP, Mor-Avi V, Afilalo J, Armstrong A, Ernande L, Flachskampf FA, Foster E, Goldstein SA, Kuznetsova T, Lancellotti P Muraru D, Picard MH, Rietzschel ER, Rudski L, Spencer KT, Tsang W, Voigt JU. Recommendations for cardiac chamber quantification by echocardiography in adults: an update from the American Society of Echocardiography and the European Association of Cardiovascular Imaging. J Am Soc Echocardiogr. 2015 Jan;28(1):1-39. e14. doi: 10.1016/j. echo.2014.10.003. PMID: 25559473.

13. Movahed MR, Ahmadi-Kashani M, Kasravi B, Saito Y. Increased prevalence of mitral stenosis in women. J Am Soc Echocardiogr. 2006 Jul;19(7):911-3. doi: 10.1016/j.echo.2006.01.017. PMID: 16825001.

14. lung $B$, Vahanian $A$. Rheumatic mitral valve disease. In: Otto CM, Bonow RO, eds. Valvular Heart Disease: A Companion to Braunwald's Heart Disease. Philadelphia: Saunders; 2013:255-277.

15. Konstam MA, Kramer DG, Patel AR, Maron MS, Udelson JE. Left ventricular remodeling in heart failure current concepts in clinical significance and assessment. JACC Cardiovascular Imaging 2011;4:98.

16. Lokhandwala YY, Banker D, Vora AM, Kerkar PG, Deshpande JR, Kulkarni $\mathrm{HL}$, Dalvi BV. Emergent balloon mitral valvotomy in patients presenting with cardiac arrest, cardiogenic shock or refractory pulmonary edema. J Am Coll Cardiol. 1998 Jul;32(1):154-8. doi: 10.1016/s0735-1097(98)00215-0. PMID: 9669264

17. Jong-Jen Wu, MD, Ming-Shyan Chern, MD, Kou-Ho Yeh, MD, YuChing Chen, MD, Morgan Fu, MD, and Jui-Sung Hung, MD. Urgent/ Emergent Catheterization and Cardiovascular Diagnosis 31:18-22 (1994) Percutaneous Transvenous Mitral Commissurotomy. Catheterization and Cardiovascular Diagnosis 31:18-22 (1994)

18. Cho IJ, Jeong H, Choi JY, Lee SE, Chang HJ. Prognostic Implications of the Left Atrial Volume Index in Patients with Progressive Mitral Stenosis. $J$ Cardiovasc Imaging. 2019;27(2):122-133. doi: 10.4250/jcvi.2019.27. e20
19. Kossaify A. Echocardiographic Assessment of the Right Ventricle, from the Conventional Approach to Speckle Tracking and Three-Dimensional Imaging, and Insights into the "Right Way" to Explore the Forgotten Chamber. Clin Med Insights Cardiol. 2015; 9:65-75. Published 2015 Jul 5. doi:10.4137/CMC.S27462

20. John A. Sallach, W.H. Wilson Tang, Allen G. Borowski, Wilson Tong, Tama Porter, Maureen G. Martin, Susan E. Jasper, Kevin Shrestha, Richard W. Troughton, Allan L. Klein, Right Atrial Volume Index in Chronic Systolic Heart Failure and Prognosis, JACC: Cardiovascular Imaging, Volume 2, Issue 5, 2009, Pages 527-534, ISSN 1936-878X, https://doi.org/10.1016/j. jcmg.2009.01.012.

21. Palacios IF, Sanchez PL, Harrell LC, Weyman AE, Block PC. Which patients benefit from percutaneous mitral balloon valvuloplasty? Prevalvuloplasty and postvalvuloplasty variables that predict long-term outcome. Circulation. 2002 Mar 26;105(12):1465-71. doi: 10.1161/01.cir.0000012143. 27196.f4. PMID: 11914256

22. Okoshi MP, Capalbo RV, Romeiro FG, Okoshi K. Cardiac Cachexia: Perspectives for Prevention and Treatment. Arq Bras Cardiol. 2017;108(1):74-80. doi:10.5935/abc.20160142

\section{APPENDIX}

\begin{tabular}{|c|c|c|}
\hline \multicolumn{3}{|c|}{$\begin{array}{l}\text { Appendix 1. Baseline echocardiographic data of severe mitral } \\
\text { stenosis with moderate to severe tricuspid regurgitation, } \\
\text { Philippine Heart Center, } 2019-2020 \text { by Category }\end{array}$} \\
\hline & No. & $\%$ \\
\hline No. of patients & 38 & -- \\
\hline \multicolumn{3}{|l|}{ LVEDD } \\
\hline Normal & 38 & 100 \\
\hline Increased & 0 & \\
\hline \multicolumn{3}{|l|}{ LVESD } \\
\hline Normal & 35 & 92.1 \\
\hline Increased & 3 & 7.9 \\
\hline \multicolumn{3}{|l|}{ LVMI } \\
\hline Normal & 31 & 81.6 \\
\hline Increased & 7 & 18.4 \\
\hline \multicolumn{3}{|l|}{ LVRT } \\
\hline Normal & 20 & 52.6 \\
\hline Increased & 18 & 47.4 \\
\hline \multicolumn{3}{|l|}{ LV Pattern } \\
\hline Normal & 17 & 44.7 \\
\hline Concentric remodeling & 14 & 36.8 \\
\hline Eccentric hypertrophy & 3 & 7.9 \\
\hline Concentric hypertrophy & 4 & 10.5 \\
\hline \multicolumn{3}{|l|}{ EF by Simpson } \\
\hline Normal & 32 & 84.2 \\
\hline Decreased & 6 & 15.8 \\
\hline \multicolumn{3}{|l|}{ LAVI } \\
\hline Mild dilatation & 1 & 2.6 \\
\hline Moderate dilatation & 6 & 15.8 \\
\hline Severe dilatation & 31 & 81.6 \\
\hline \multicolumn{3}{|l|}{ RAVI } \\
\hline Normal & 20 & 52.6 \\
\hline Increased & 18 & 47.4 \\
\hline \multicolumn{3}{|l|}{ RVFAC } \\
\hline Normal & 33 & 86.8 \\
\hline Decreased & 5 & 13.2 \\
\hline \multicolumn{3}{|l|}{ RVD mid } \\
\hline Normal & 28 & 73.7 \\
\hline Increased & 10 & 26.3 \\
\hline \multicolumn{3}{|l|}{ PA Pressure } \\
\hline Mild & 15 & 39.5 \\
\hline Moderate & 12 & 31.6 \\
\hline Severe & 11 & 28.9 \\
\hline \multicolumn{3}{|l|}{ MR } \\
\hline None & 12 & 31.6 \\
\hline Mild & 21 & 55.3 \\
\hline Moderate & 5 & 13.2 \\
\hline
\end{tabular}




\begin{tabular}{|c|c|c|}
\hline \multicolumn{3}{|c|}{$\begin{array}{l}\text { Appendix 1. Baseline echocardiographic data of severe mitral } \\
\text { stenosis with moderate to severe tricuspid regurgitation, } \\
\text { Philippine Heart Center, 2019-2020 by Category }\end{array}$} \\
\hline & No. & $\%$ \\
\hline \multicolumn{3}{|l|}{ TR } \\
\hline Mild & 0 & 0 \\
\hline Moderate & 27 & 71.1 \\
\hline Severe & 11 & 28.9 \\
\hline \multicolumn{3}{|c|}{ Tricuspid valve annulus } \\
\hline Normal & 17 & 44.7 \\
\hline Increased & 21 & 55.3 \\
\hline \multicolumn{3}{|c|}{ Aortic regurgitation } \\
\hline None & 16 & 42.1 \\
\hline Mild & 8 & 21.1 \\
\hline Moderate & 14 & 36.8 \\
\hline \multicolumn{3}{|l|}{ Aortic stenosis } \\
\hline None & 35 & 92.1 \\
\hline Present & 3 & 7.9 \\
\hline \multicolumn{3}{|c|}{ Pulmonic regurgitation } \\
\hline None & 5 & 13.2 \\
\hline Present & 33 & 86.8 \\
\hline \multicolumn{3}{|c|}{ Pulmonic valve annulus } \\
\hline Normal & 21 & 55.3 \\
\hline Increased & 17 & 44.7 \\
\hline \multicolumn{3}{|l|}{ LVOT } \\
\hline Normal & 28 & 73.7 \\
\hline Decreased & 10 & 26.3 \\
\hline \multicolumn{3}{|l|}{ RVOT } \\
\hline Normal & 33 & 86.8 \\
\hline Increased & 5 & 13.2 \\
\hline
\end{tabular}

\begin{tabular}{|c|c|c|c|}
\hline \multicolumn{4}{|c|}{$\begin{array}{l}\text { Appendix 2. Comparison in Echocardiographic data of Significant } \\
\text { and Insignificant Tricuspid Regurgitation from baseline to 24th } \\
\text { hour after PMC, Philippine Heart Center, 2019-2020 }\end{array}$} \\
\hline & Significant & $\begin{array}{l}\text { Non- } \\
\text { Significant }\end{array}$ & p-value \\
\hline No. of patients & $6(\%)$ & $32(\%)$ & - \\
\hline \multicolumn{4}{|l|}{ LVEDD } \\
\hline Normal & $6(15.8)$ & $32(84.2)$ & -- \\
\hline Increased & 0 & 0 & \\
\hline \multicolumn{4}{|l|}{ LVESD } \\
\hline Normal & $5(14.3)$ & $30(85.7)$ & .35 \\
\hline Increased & $1(33.3)$ & $2(66.7)$ & \\
\hline \multicolumn{4}{|l|}{ LVMI } \\
\hline Normal & $5(15.6)$ & 27 (84.4) & .95 \\
\hline Increased & $1(16.7)$ & $5(83.3)$ & \\
\hline \multicolumn{4}{|l|}{ LVRT } \\
\hline Normal & $5(18.5)$ & $22(81.5)$ & .47 \\
\hline Increased & $1(9.1)$ & $10(90.9)$ & \\
\hline \multicolumn{4}{|l|}{ LV Pattern } \\
\hline Normal & $4(16.7)$ & 20 (83.3) & .72 \\
\hline Concentric remodeling & $1(12.5)$ & $7(87.5)$ & \\
\hline Eccentric hypertrophy & $1(33.3)$ & $2(66.7)$ & \\
\hline Concentric hypertrophy & 0 & $3(100)$ & \\
\hline \multicolumn{4}{|l|}{ EF by Simpson } \\
\hline Normal & $6(16.7)$ & $30(83.3)$ & .52 \\
\hline Decreased & 0 & $2(100)$ & \\
\hline \multicolumn{4}{|l|}{ LAVI } \\
\hline Normal & $2(50)$ & $2(50)$ & .21 \\
\hline Mild dilatation & 0 & $5(100)$ & \\
\hline Moderate dilatation & $1(14.3)$ & $6(85.7)$ & \\
\hline Severe dilatation & $3(13.6)$ & $19(86.4)$ & \\
\hline
\end{tabular}

\begin{tabular}{|c|c|c|c|}
\hline \multicolumn{4}{|c|}{$\begin{array}{l}\text { Appendix 2. Comparison in Echocardiographic data of Significant } \\
\text { and Insignificant Tricuspid Regurgitation from baseline to 24th } \\
\text { hour after PMC, Philippine Heart Center, 2019-2020 }\end{array}$} \\
\hline & Significant & $\begin{array}{l}\text { Non- } \\
\text { Significant }\end{array}$ & $p$-value \\
\hline \multicolumn{4}{|l|}{ RAVI } \\
\hline Normal & 0 & $20(100)$ & .005 \\
\hline Increased & $6(33.3)$ & $12(66.7)$ & \\
\hline \multicolumn{4}{|l|}{ RVFAC } \\
\hline Normal & $4(11.1)$ & 32 (89.9) & .001 \\
\hline Decreased & $2(100)$ & $0(0)$ & \\
\hline \multicolumn{4}{|l|}{ RVD mid } \\
\hline Normal & $2(6.5)$ & 29 (93.5) & .001 \\
\hline Increased & $4(57.1)$ & $3(42.9)$ & \\
\hline \multicolumn{4}{|l|}{ PA Pressure } \\
\hline Normal & $0(0)$ & $13(100)$ & .052 \\
\hline Mild & $3(15.8)$ & $16(84.2)$ & \\
\hline Moderate & $2(50)$ & $2(50)$ & \\
\hline Severe & $1(50)$ & $1(50)$ & \\
\hline \multicolumn{4}{|l|}{ Mitral regurgitation } \\
\hline None & $3(21.4)$ & $11(78.6)$ & .79 \\
\hline Mild & $2(14.3)$ & $12(85.7)$ & \\
\hline Moderate & $1(12.5)$ & $7(87.5)$ & \\
\hline Severe & 0 & $2(100)$ & \\
\hline \multicolumn{4}{|c|}{ Tricuspid regurgitation } \\
\hline None & 0 & $8(100)$ & .001 \\
\hline Mild & 0 & $12(100)$ & \\
\hline Moderate & 0 & $12(100)$ & \\
\hline Severe & $6(100)$ & 0 & \\
\hline \multicolumn{4}{|c|}{ Tricuspid valve annulus } \\
\hline Normal & 0 & $18(100)$ & .011 \\
\hline Increased & $6(30)$ & $14(70)$ & \\
\hline \multicolumn{4}{|c|}{ Aortic regurgitation } \\
\hline None & $2(12.5)$ & $14(87.5)$ & .88 \\
\hline Mild & $3(18.8)$ & $13(81.3)$ & \\
\hline Moderate & $1(16.7)$ & $5(83.3)$ & \\
\hline \multicolumn{4}{|l|}{ Aortic stenosis } \\
\hline None & $6(17.1)$ & 29 (82.9) & .44 \\
\hline Present & 0 & $3(100)$ & \\
\hline \multicolumn{4}{|c|}{ Pulmonic regurgitation } \\
\hline Normal & 0 & $10(100)$ & .11 \\
\hline Increased & $6(18.2)$ & $22(78.6)$ & \\
\hline \multicolumn{4}{|c|}{ Pulmonic valve annulus } \\
\hline Normal & $4(16.0)$ & $21(84.0)$ & .77 \\
\hline Increased & $2(15.4)$ & $11(84.6)$ & \\
\hline \multicolumn{4}{|l|}{ LVOT } \\
\hline Normal & $3(13)$ & $20(87)$ & .56 \\
\hline Decreased & $3(20)$ & $12(80)$ & \\
\hline \multicolumn{4}{|l|}{ RVOT } \\
\hline Normal & $6(16.2)$ & $31(83.8)$ & .11 \\
\hline Increased & 0 & $1(100)$ & \\
\hline
\end{tabular}

Values in parentheses reflect horizontal sum, Significant $p$-value if $<.05$, Chi-Square Test Dashes indicate not calculatable p-values 


\begin{tabular}{|c|c|c|c|}
\hline \multicolumn{4}{|c|}{$\begin{array}{l}\text { Appendix 3. Echocardiographic data from 24th hour to } 1 \text { st month } \\
\text { after PMC in Tricuspid Regurgitation, Philippine Heart Center, } \\
2019-2021\end{array}$} \\
\hline & Significant & $\begin{array}{l}\text { Non- } \\
\text { Significant }\end{array}$ & p-value \\
\hline No. of patients & $8(\%)$ & $21(\%)$ & \\
\hline \multicolumn{4}{|l|}{ LVEDD } \\
\hline Normal & $8(27.6)$ & $21(72.4)$ & -- \\
\hline Increased & 0 & 0 & \\
\hline \multicolumn{4}{|l|}{ LVESD } \\
\hline Normal & $5(20)$ & $20(80)$ & .11 \\
\hline Increased & $3(75)$ & $1(25)$ & \\
\hline \multicolumn{4}{|l|}{ LVMI } \\
\hline Normal & $5(21.7)$ & $18(78.3)$ & .17 \\
\hline Increased & $3(50)$ & $3(50)$ & \\
\hline \multicolumn{4}{|l|}{ LVRT } \\
\hline Normal & $6(33.3)$ & $12(66.7)$ & .37 \\
\hline Increased & $2(18.2)$ & $9(81.8)$ & \\
\hline \multicolumn{4}{|l|}{ LV Pattern } \\
\hline Normal & $4(25)$ & $12(75)$ & .11 \\
\hline Concentric remodeling & $1(14.3)$ & $6(85.7)$ & \\
\hline Eccentric hypertrophy & $2(100)$ & 0 & \\
\hline Concentric hypertrophy & $1(25)$ & $3(75)$ & \\
\hline \multicolumn{4}{|l|}{ EF by Simpson } \\
\hline Normal & $8(27.6)$ & $21(72.4)$ & -- \\
\hline Decreased & 0 & 0 & \\
\hline \multicolumn{4}{|l|}{ LAVI } \\
\hline Normal & 0 & 4 & .26 \\
\hline Mild dilatation & $2(66.7)$ & 1 (933.3) & \\
\hline Moderate dilatation & $1(20)$ & $4(80)$ & \\
\hline Severe dilatation & $5(29.4)$ & $12(70.6)$ & \\
\hline \multicolumn{4}{|l|}{ RAVI } \\
\hline Normal & $4(20)$ & $16(80)$ & .17 \\
\hline Increased & $4(44.4)$ & $5(55.6)$ & \\
\hline \multicolumn{4}{|l|}{ RVFAC } \\
\hline Normal & $7(25)$ & $21(75)$ & .099 \\
\hline Decreased & $1(100)$ & 0 & \\
\hline \multicolumn{4}{|l|}{ RVD mid } \\
\hline Normal & $5(19.2)$ & $21(80.8)$ & .003 \\
\hline Increased & $3(100)$ & 0 & \\
\hline \multicolumn{4}{|l|}{ PA Pressure } \\
\hline Normal & $1(10)$ & $9(90)$ & .42 \\
\hline Mild & $5(33.3)$ & $10(66.7)$ & \\
\hline Moderate & $1(50)$ & $1(50)$ & \\
\hline Severe & $1(50)$ & $1(50)$ & \\
\hline \multicolumn{4}{|l|}{ Mitral regurgitation } \\
\hline None & $2(28.6)$ & $5(71.4)$ & .40 \\
\hline Mild & $3(27.3)$ & $8(72.7)$ & \\
\hline Moderate & $2(20)$ & $8(80)$ & \\
\hline Severe & $1(100)$ & 0 & \\
\hline \multicolumn{4}{|l|}{ Tricuspid regurgitation } \\
\hline None & 0 & $1(100)$ & .021 \\
\hline Mild & $1(6.3)$ & 15 (93.8) & \\
\hline Moderate & $4(44.4)$ & $5(55.6)$ & \\
\hline Severe & $3(100)$ & 0 & \\
\hline \multicolumn{4}{|l|}{ Tricuspid valve annulus } \\
\hline Normal & $2(14.3)$ & $12(85.7)$ & .12 \\
\hline Increased & $6(40)$ & $9(60)$ & \\
\hline \multicolumn{4}{|l|}{ Aortic regurgitation } \\
\hline None & $2(25)$ & $6(75)$ & .42 \\
\hline Mild & $5(38.5)$ & $8(61.5)$ & \\
\hline Moderate & $1(12.5)$ & $7(87.5)$ & \\
\hline Aortic stenosis & & & \\
\hline None & $8(29.6)$ & $19(70.4)$ & .36 \\
\hline Present & 0 & $2(100)$ & \\
\hline
\end{tabular}

\begin{tabular}{|c|c|c|c|}
\hline \multicolumn{4}{|c|}{$\begin{array}{l}\text { Appendix 3. Echocardiographic data from 24th hour to 1st month } \\
\text { after PMC in Tricuspid Regurgitation, Philippine Heart Center, } \\
\text { 2019-2021 }\end{array}$} \\
\hline & Significant & $\begin{array}{l}\text { Non- } \\
\text { Significant }\end{array}$ & p-value \\
\hline \multicolumn{4}{|c|}{ Pulmonic regurgitation } \\
\hline Normal & $1(20)$ & $4(80)$ & .67 \\
\hline Increased & $7(29.2)$ & $17(70.8)$ & \\
\hline \multicolumn{4}{|c|}{ Pulmonic valve annulus } \\
\hline Normal & $6(30)$ & $14(70)$ & .66 \\
\hline Increased & $2(22.2)$ & $7(77.8)$ & \\
\hline \multicolumn{4}{|l|}{ LVOT } \\
\hline Normal & $5(25)$ & $15(75)$ & .64 \\
\hline Decreased & $3(33.3)$ & $6(66.7)$ & \\
\hline \multicolumn{4}{|l|}{ RVOT } \\
\hline Normal & $8(32)$ & $17(68)$ & .18 \\
\hline Increased & 0 & $4(100)$ & \\
\hline
\end{tabular}

Values in parentheses reflect horizontal sum, Significant $p$-value if $<.05$, Chi-Square Test Dashes indicate not calculatable p-values

\begin{tabular}{|c|c|c|c|}
\hline \multicolumn{4}{|c|}{$\begin{array}{l}\text { Appendix 4. Echocardiographic data from 1st to 6th month after } \\
\text { PMC in Tricuspid Regurgitation, Philippine Heart Center, 2019- } \\
2021\end{array}$} \\
\hline & Significant & $\begin{array}{l}\text { Non- } \\
\text { Significant }\end{array}$ & p-value \\
\hline No. of patients & $1(\%)$ & $18(\%)$ & \\
\hline LVEDD & & & .003 \\
\hline Normal & 0 & $17(100)$ & \\
\hline Increased & $1(50)$ & $1(50)$ & \\
\hline \multicolumn{4}{|l|}{ LVESD } \\
\hline Normal & $1(5.9)$ & $16(94.1)$ & .72 \\
\hline Increased & 0 & $2(100)$ & \\
\hline \multicolumn{4}{|l|}{ LVMI } \\
\hline Normal & $1(6.3)$ & $15(93.8)$ & .65 \\
\hline Increased & 0 & $3(100)$ & \\
\hline \multicolumn{4}{|l|}{ LVRT } \\
\hline Normal & 0 & $14(100)$ & .08 \\
\hline Increased & $1(20)$ & $4(80)$ & \\
\hline \multicolumn{4}{|l|}{ LV Pattern } \\
\hline Normal & 0 & $12(100)$ & .26 \\
\hline Concentric remodeling & $1(25)$ & $3(75)$ & \\
\hline Eccentric hypertrophy & 0 & $2(100)$ & \\
\hline Concentric hypertrophy & 0 & $1(100)$ & \\
\hline \multicolumn{4}{|l|}{ EF by Simpson } \\
\hline Normal & $1(5.3)$ & $18(94.7)$ & -- \\
\hline Decreased & 0 & 0 & \\
\hline \multicolumn{4}{|l|}{ LAVI } \\
\hline Normal & 0 & $2(100)$ & .76 \\
\hline Mild dilatation & 0 & $5(100)$ & \\
\hline Moderate dilatation & 0 & $3(100)$ & \\
\hline Severe dilatation & $1(11.1)$ & $8(88.9)$ & \\
\hline \multicolumn{4}{|l|}{ RAVI } \\
\hline Normal & 0 & $12(100)$ & .18 \\
\hline Increased & $1(14.3)$ & $6(85.7)$ & \\
\hline \multicolumn{4}{|l|}{ RVFAC } \\
\hline Normal & $1(5.6)$ & $17(94.4)$ & .81 \\
\hline Decreased & 0 & $1(100)$ & \\
\hline \multicolumn{4}{|l|}{ RVD mid } \\
\hline Normal & 0 & $18(100)$ & .001 \\
\hline Increased & $1(100)$ & 0 & \\
\hline \multicolumn{4}{|l|}{ PA Pressure } \\
\hline Normal & 0 & $5(100)$ & .78 \\
\hline Mild & $1(7.7)$ & $12(92.3)$ & \\
\hline
\end{tabular}




\begin{tabular}{|c|c|c|c|}
\hline \multicolumn{4}{|c|}{$\begin{array}{l}\text { Appendix 4. Echocardiographic data from 1st to 6th month after } \\
\text { PMC in Tricuspid Regurgitation, Philippine Heart Center, 2019- } \\
2021\end{array}$} \\
\hline & Significant & $\begin{array}{l}\text { Non- } \\
\text { Significant }\end{array}$ & p-value \\
\hline Moderate & 0 & $1(100)$ & \\
\hline Severe & 0 & 0 & \\
\hline \multicolumn{4}{|c|}{ Mitral regurgitation } \\
\hline None & $1(20)$ & $4(80)$ & .39 \\
\hline Mild & 0 & $8(100)$ & \\
\hline Moderate & 0 & $4(100)$ & \\
\hline Severe & 0 & $2(100)$ & \\
\hline \multicolumn{4}{|c|}{ Tricuspid regurgitation } \\
\hline None & 0 & $1(100)$ & .001 \\
\hline Mild & 0 & $13(100)$ & \\
\hline Moderate & 0 & $4(100)$ & \\
\hline Severe & $1(100)$ & 0 & \\
\hline \multicolumn{4}{|c|}{ Tricuspid valve annulus } \\
\hline Normal & 0 & $12(100)$ & .18 \\
\hline Increased & $1(14.3)$ & $6(85.7)$ & \\
\hline \multicolumn{4}{|c|}{ Aortic regurgitation } \\
\hline None & 0 & $3(100)$ & .68 \\
\hline Mild & $1(9.1)$ & $10(90.9)$ & \\
\hline Moderate & 0 & $5(100)$ & \\
\hline \multicolumn{4}{|l|}{ Aortic stenosis } \\
\hline None & $1(5.6)$ & $17(94.4)$ & .81 \\
\hline Present & 0 & $1(100)$ & \\
\hline \multicolumn{4}{|c|}{ Pulmonic regurgitation } \\
\hline Normal & 0 & $3(100)$ & .66 \\
\hline Increased & $1(6.3)$ & $15(93.8)$ & \\
\hline \multicolumn{4}{|c|}{ Pulmonic valve annulus } \\
\hline Normal & 0 & $16(100)$ & .018 \\
\hline Increased & $1(33.3)$ & $2(66.7)$ & \\
\hline \multicolumn{4}{|l|}{ LVOT } \\
\hline Normal & $1(6.3)$ & $15(93.8)$ & .65 \\
\hline Decreased & 0 & $3(100)$ & \\
\hline \multicolumn{4}{|l|}{ RVOT } \\
\hline Normal & 0 & $18(100)$ & .001 \\
\hline Increased & $1(100)$ & 0 & \\
\hline
\end{tabular}

\begin{tabular}{|c|c|c|c|}
\hline \multicolumn{4}{|c|}{$\begin{array}{l}\text { Appendix 5. Comparison in Characteristics of Significant and } \\
\text { Insignificant Tricuspid Regurgitation from 24th to 1st after PTMC, } \\
\text { Philippine Heart Center, 2019-2020 }\end{array}$} \\
\hline Characteristics & $\begin{array}{l}\text { Significant } \\
\text { TR }\end{array}$ & $\begin{array}{l}\text { Non- } \\
\text { Significant TR }\end{array}$ & p-value \\
\hline Age & 39.6 & 43.1 & .50 \\
\hline \multicolumn{4}{|l|}{ Sex } \\
\hline Male & $1(16.7)$ & $5(83.3)$ & .94 \\
\hline Female & $5(15.6)$ & $27(84.4)$ & \\
\hline \multicolumn{4}{|l|}{ NYHA } \\
\hline I & $5(13.5)$ & $32(86.5)$ & $.019^{\star *}$ \\
\hline II & 0 & 0 & \\
\hline III & 0 & 0 & \\
\hline IV & $1(100)$ & 0 & \\
\hline \multicolumn{4}{|l|}{ Rhythm } \\
\hline SR & $2(16.7)$ & 10 (83.3) & .06 \\
\hline $\mathrm{AF}$ & $3(12)$ & $22(88)$ & \\
\hline Height (meters) & $1.6(.07)$ & $1.57(.05)$ & .24 \\
\hline Weight (kg) & $45(23.1)$ & $57.5(8.0)$ & $.018^{*}$ \\
\hline \multicolumn{4}{|l|}{ Body mass index } \\
\hline Underweight & 0 & $1(100)$ & .50 \\
\hline Normal & $5(16.7)$ & 25 (83.3) & \\
\hline Overweight & 0 & $6(1000)$ & \\
\hline Obese & 0 & 0 & \\
\hline
\end{tabular}

Significant difference if $p$-value is $<.05$, * Mann Whitney $U$ test, ** Chi-Square Test

Values in parentheses reflect horizontal sum, Significant p-value if $<.05$, Chi-Square Test Dashes indicate not calculatable p-values 